\title{
Pulse methylprednisolone therapy in rheumatoid arthritis: Unproved therapy, unjustified therapy, or effective adjunctive treatment?
}

\author{
M D Smith, M J Ahern, P J Roberts-Thomson
}

The introduction of corticosteroids and their use in the treatment of rheumatoid arthritis (RA) over 30 years ago was greeted with an initial enthusiasm, which was later tempered by the significant side effects resulting from such treatment. Oral corticosteroids are now usually reserved for severe refractory RA, treatment of elderly patients, extra-articular features (vasculitis, pericarditis), or as short term treatment for social, work, or family reasons. Recent interest in chronic low dose oral corticosteroid treatment in $\mathrm{RA}$, however, has resulted in an editorial ${ }^{1}$ and several letters ${ }^{2}$ suggesting a more widespread use of such treatment, with possibly less toxicity than previously thought. Intra-articular corticosteroids still have a most important place in the treatment of RA. Although a temporary systemic effect on other inflamed joints can result from a single corticosteroid injection, it is unpredictable, usually requires large doses of intra-articular steroids injected into multiple joints, and may lead to hypothalamic-pituitary axis suppression. ${ }^{3-5}$

After the successful use of high dose intravenous boluses of methylprednisolone succinate in the treatment of renal transplant rejection and diffuse proliferative glomerulonephritis in patients with systemic lupus erythematosus, several studies were published in the early part of this decade reporting the short term (and occasionally long term) efficacy of pulse therapy in RA. ${ }^{6-12}$ In these initial studies patients offered this treatment were those with RA refractory to all other treatments, including several remittive agents. Even in this refractory group impressive reductions in clinical and laboratory indices of disease activity were achieved.

More recent studies have advocated treating patients with RA at an earlier stage in their disease, often in combination with remittive agents such as sodium aurothiomalate, Dpenicillamine, sulphasalazine, and azathioprine. ${ }^{911-13}$ All these studies reported an average duration of response of at least six to eight weeks for pulse therapy alone, with significant prolongation of the response when combined with a remittive agent (table), thus effectively bridging the gap between initiation and response with these agents. ${ }^{14-16}$

Even more impressive is the favourable risk/ benefit ratio of pulse therapy, with few minor or major adverse effects resulting from methyl- prednisolone infusion therapy (table). Most of the serious adverse effects-cardiovascular collapse, myocardial infarction, severe infectionhave occurred in patients with compromised cardiovascular or immune systems as a result of the disease being treated or due to concomitant drug treatment. Most of the recent studies of pulse therapy in $\mathrm{RA}^{6} 79121317-21$ have been unable to confirm the $24 \%$ incidence of 'adverse effects requiring medical intervention' reported in an earlier study by Garrett and Paulus. ${ }^{22}$ Such a high incidence of adverse effects from pulse therapy was not even confirmed in a later study from the same authors. ${ }^{6}$ Even the theoretical risk of osteonecrosis (due to the large total dose of corticosteroids used in pulse therapy) does not appear to be enhanced according to a recently reported retrospective, randomised, double blind, matched cohort survey. ${ }^{20}$ The same authors, however, reported three cases of avascular necrosis following pulse therapy, two of which might have been related to the treatment. ${ }^{13}$ Two further cases of avascular necrosis following pulse therapy have been reported, ${ }^{23}$ but neither of these reports distinguishes between treatment and disease related avascular necrosis or allows for the effect of other treatments (previous oral or intra-articular steroids). A prospective study is required to answer this important issue but the incidence of this theoretical complication of pulse therapy seems unlikely to be significantly increased in patients with RA receiving pulse therapy compared with those who are not.

Studies of bone metabolism during pulse therapy ${ }^{24} 25$ have concluded that this treatment does not seriously affect bone metabolism in the short term, suggesting that osteoporosis is unlikely to be a significant long term complication. An assessment of the toxicity of pulse therapy in the treatment of RA can be made by summating the reported side effects in published studies (table). Minor adverse reactions occurred in $14 \%$ (68 of 480 patients with RA treated with intravenous pulse therapy) while major side effects occurred in $2 \%$ (10 of 480 patients with RA). This is likely to be an overestimation as it assumes one pulse treatment per patient (whereas in some studies several pulse treatments were given, all of which could result in adverse effects) and includes two studies reporting much higher incidences of adverse effects, ${ }^{13} 22$ which will bias the results in favour 
Reports of methylprednisolone pulse therapy in rheumatoid arthritis

\begin{tabular}{|c|c|c|c|c|c|c|}
\hline \multirow[t]{2}{*}{ Reference } & \multirow{2}{*}{$\begin{array}{l}\text { Number } \\
\text { of patients } \\
\text { studied }\end{array}$} & \multirow{2}{*}{$\begin{array}{l}\text { Concomitant or } \\
\text { previous treatment }\end{array}$} & \multirow{2}{*}{$\begin{array}{l}\text { Type of } \\
\text { pulse therapy }\end{array}$} & \multirow{2}{*}{$\begin{array}{l}\text { Mean duration } \\
\text { of response } \\
\text { (weeks) }\end{array}$} & \multicolumn{2}{|c|}{ Adverse effects } \\
\hline & & & & & Major & Minor \\
\hline Fan et al, $1978^{32}$ & 12 & $\begin{array}{l}\text { Failed gold, } \\
\text { No oral steroids }\end{array}$ & $1 \mathrm{~g} \mathrm{IV}^{*}$ or $1 \mathrm{~g} \mathrm{IV} \times 3$ & $4-6 \dagger$ & 0 & 7 \\
\hline Garrett and Paulus, & $\left.\begin{array}{ll}50 & \\
(21 & R A\end{array}\right)^{*}$ & $\begin{array}{l}\text { Oral steroids (21) } \\
\text { Cytotoxics (10) }\end{array}$ & Variable and multiple & Not stated & 128 & 16 \\
\hline Liebling et al, $1981^{6}$ & 10 & $\begin{array}{l}\text { Gold (2) } \\
\text { Penicillamine (2) } \\
\text { Oral steroids (5) } \\
\text { IA }^{*} \text { steroids (7) }\end{array}$ & $1 \mathrm{~g}$ IV monthly for 6 months & $11 \cdot 6$ & 0 & 5 \\
\hline Forster et al, $1982^{7}$ & 14 & $\begin{array}{l}\text { Sulphasalazine (2) } \\
\text { Penicillamine (2) } \\
\text { Oral steroids (6) } \\
\text { IM }^{*} \text { steroids (1) }\end{array}$ & $1 \mathrm{~g} \mathrm{IV} \times 3$ & $10 \ddagger$ & 1 & 1 \\
\hline Williams et al, $1982^{8}$ & $\begin{array}{l}20 \\
(10 \text { placebo })\end{array}$ & $\begin{array}{l}\text { Gold (2) } \\
\text { No oral steroids }\end{array}$ & $1 \mathrm{~g} \mathrm{IV}$ & $>6$ & 0 & 1 \\
\hline Baylis et al, $1982^{28}$ & & $\begin{array}{l}\text { No oral steroids } \\
\text { No DMARDs* }\end{array}$ & $1 \mathrm{~g} \mathrm{IV} \times 3$ & 12 & \multicolumn{2}{|c|}{$\begin{array}{l}\text { No side effects } \\
\text { reported }\end{array}$} \\
\hline Neumann et al, $1985^{9}$ & 45 & $\begin{array}{l}\text { No previous steroids, } \\
\text { penicillamine, or } \\
\text { sulphasalazine }\end{array}$ & $\begin{array}{l}1 \mathrm{~g} \mathrm{IV} \times 3 \text { with or without } \\
\text { penicillamine or } \\
\text { sulphasalazine }\end{array}$ & $\begin{array}{l}8 \text {, with pulse alone } \\
>24 \text {, with pulse } \\
\text { plus DMARD }\end{array}$ & 0 & 0 \\
\hline Hansen et al, 1987'1 & $\begin{array}{l}30 \\
(15 \text { placebo })\end{array}$ & $\begin{array}{l}\text { No recent DMARD } \\
\text { Oral steroids allowed }\end{array}$ & $\begin{array}{l}1 \mathrm{~g} \text { IV } \times 3 \\
+ \text { gold }(7) \\
+ \text { penicillamine }(5) \\
\text { + azathioprine (3) }\end{array}$ & $\begin{array}{l}\text { Uncertain, } \\
\text { around } 4-8\end{array}$ & \multicolumn{2}{|c|}{ Not reported } \\
\hline Shipley et al, $1988^{13}$ & 71 & $\begin{array}{l}\text { No oral steroids or } \\
\text { DMARDs }\end{array}$ & $40 \mathrm{mg}, 500 \mathrm{mg}$ or $1 \mathrm{~g} \mathrm{IV}$ & $\begin{array}{l}<3 \text {, with } 40 \text { or } \\
500 \mathrm{mg} \\
12 \text {, with } 1 \mathrm{~g}\end{array}$ & 3 & 38 \\
\hline $\begin{array}{l}\text { Walters and Cawley, } \\
1988^{19}\end{array}$ & 17 & $\begin{array}{l}\text { Unresponsive to DMARDs } \\
\text { No oral steroids }\end{array}$ & $\begin{array}{l}1 \text { g IV alone (5) } \\
+ \text { IV cyclophosphamide (4) } \\
+ \text { IM gold (4) } \\
+ \text { IM gold and IV } \\
\text { cyclophosphamide (4) }\end{array}$ & $\begin{array}{l}12 \text {, without gold } \\
>24 \text {, with gold }\end{array}$ & 1 & 1 \\
\hline Williams et al, $1988^{20}$ & 143 & $\begin{array}{l}\text { Retrospective study } \\
\text { No oral steroids }\end{array}$ & Variable and multiple & Uncertain & \multicolumn{2}{|c|}{$\begin{array}{l}\text { Similar in both } \\
\text { treated and } \\
\text { control groups }\end{array}$} \\
\hline Needs et al, $1988^{18}$ & 14 & $\begin{array}{l}\text { Oral steroids allowed } \\
\text { No IA steroids }\end{array}$ & $\begin{array}{l}1 \mathrm{~g} \mathrm{IV} \times 3 \text { or } 1 \mathrm{~g} \times 3 \\
\text { oral prednisolone }\end{array}$ & Less than 6 & 0 & 8 \\
\hline Radia and Furst, $1988^{21}$ & 29 & $\begin{array}{l}\text { No recent DMARDs, oral } \\
\text { or IA steroids }\end{array}$ & $\begin{array}{l}1 \mathrm{~g} \text { or } 320 \mathrm{mg} \mathrm{IV} \\
\text { or } 320 \mathrm{mg} \mathrm{IM}\end{array}$ & $3-6$ & \multicolumn{2}{|c|}{ None found } \\
\hline Smith et al, $1988^{17}$ & $24 \|$ & $\begin{array}{l}\text { No oral or IA steroids } \\
\text { DMARDs allowed }\end{array}$ & $1 \underset{\text { prednisolone }}{\mathrm{g} \mathrm{IV}} \times 3$ or $1 \mathrm{~g} \times 3$ oral & $13-14$ & 11 & 19 \\
\hline Smith et al, $1988^{12}$ & $40 \|$ & $\begin{array}{l}\text { No oral or IA steroids } \\
\text { DMARDs allowed }\end{array}$ & $\begin{array}{l}1 \mathrm{~g} \text { IV alone or } \\
1 \mathrm{~g} \text { IV + established } \\
\text { or new DMARD }\end{array}$ & $\begin{array}{l}5 \cdot 1 \\
16 \\
>24\end{array}$ & 19 & 29 \\
\hline
\end{tabular}

*RA=rheumatoid arthritis; IA = intra-articular; IM=intramuscular; DMARDs=disease modifying antirheumatic drugs; IV=intravenous.

†Duration $>10$ weeks for two patients.

fDuration long term for two patients.

Four in patients with RA.

ITwelve patients reported in another study.

† Same adverse effect reported in two studies.

of a higher rate of toxicity. Also many of the minor adverse effects reported were relatively trivial (facial flushing, pyschological disturbance, palpitations, taste disturbance) and self limited.

On balance then, methylprednisolone pulse therapy is an effective safe treatment for the suppression of the acute inflammatory process in RA and may be usefully combined with disease modifying agents to gain rapid control of the inflammatory process while waiting for a response to the remittive agents. Although it is possible that the combination of methylprednisolone pulse therapy with a remittive agent might improve the efficacy of the latter with reduced adverse effects and increased efficacy, resulting in lower dropout rates from long term remittive treatment, there is little evidence to suggest that methylprednisolone pulse therapy has any disease remission properties on its own. The short duration of response makes pulse therapy an unsatisfactory long term treatment for RA, except in those patients refractory to all other treatments.

The mechanism of action of pulse therapy is uncertain, but marked reductions in $\mathrm{C}$ reactive protein and immune complex concentrations in peripheral blood 79101726 and synovial fluid ${ }^{1027}$ as well as significant effects on cellular traffic $^{10}{ }^{27}$ have been found. Although this treatment does alter $\mathrm{T}$ lymphocyte subpopulations in peripheral blood and synovial fluid, ${ }^{10} 2627$ such effects are temporary and cannot explain either the rapid onset or the prolonged duration of clinical response to this treatment. Similarly, there is no simple pharmacokinetic or pharmacodynamic explanation for the prolonged action of pulse therapy. ${ }^{1828}$

The minimal effective dose of methylprednisolone is uncertain at present. While one study has suggested that doses as low as $\mathbf{3 2 0} \mathbf{~ m g}$ intravenously or intramuscularly are as effective as $1 \mathrm{~g}$ intravenous methylprednisolone, ${ }^{21}$ another study has shown that reduction of the intravenous methylprednisolone dose from $1 \mathrm{~g}$ to $500 \mathrm{mg}$ results in a substantial loss of efficacy. ${ }^{13}$ There seems little advantage in giving three consecutive pulses of methylprednisolone rather than a single pulse, which could be repeated if necessary while awaiting the response to a remittive agent. The demonstration that equivalent amounts of oral prednisolone are as effective as intravenous 
methylprednisolone ${ }^{17}$ will allow pulse therapy to become an outpatient procedure, with considerable reductions in treatment costs, patient discomfort, and adverse effects related to the intravenous route of administration. If oral (or intravenous) pulse therapy is given too often, however, there would be no advantage over chronic low dose prednisolone therapy with its resulting long term adverse effects. Whether pulse therapy given intravenously or orally is significantly more efficacious or less toxic than low dose oral corticosteroids or intermittent intra-articular corticosteroids is uncertain as no studies have considered this issue. A method of giving corticosteroids which leads to rapid (if temporary) relief of articular inflammation, with a low incidence of adverse effects and no prolonged suppressive effects on the hypothalamic-pituitary axis ${ }^{28}$ or bone metabolism ${ }^{24} 25$ is likely to be more acceptable than treatments with significant potentially adverse effects resulting from long term use (oral steroids) or the route of administration (intra-articular steroids).

There is a critical lack of studies considering the risk/benefit ratio of non-steroidal antiinflammatory drug treatment and comparing it with alternative methods of controlling acute inflammation, including intermittent pulse therapy (oral, intravenous, or intra-articular). Despite the efficacy of such treatment and its favourable risk/benefit ratio, methylprednisolone therapy has been described as 'unproved therapy', ${ }^{29}$ 'hardly justifiable treatment', ${ }^{30}$ 'having unknown merits in comparison to other acute pharmacologic and physical therapies, ${ }^{31}$ and 'to be of little or no value in the long term treatment of rheumatoid arthritis'.11 Such excessive therapeutic conservatism is somewhat surprising in view of the significant adverse effects (gastrointestinal intolerance, peptic ulcer, renal dysfunction) and relatively low efficacy of non-steroidal anti-inflammatory drugs and the slow onset of action, high incidence of minor and major side effects and high drop out rates with current remittive agents. ${ }^{33}$ Although improvements in the treatment of RA will rely on an understanding of the aetiological and pathophysiological mechanisms involved in the chronic inflammatory process, pulse methylprednisolone therapy has surely earned a place in the therapeutic regimens for RA, preferably in combination with suitable disease modifying agents. Pulse methylprednisolone therapy in RA-unproved therapy, unjustified therapy, or effective adjunctive treatment?-you be the judge.

1 Myles A. Corticosteroid treatment in rheumatoid arthritis. $\mathrm{Br}$ f Rheumatol 1985; 24: 125-7.

2 Capell $\mathrm{H}$, Hunter $\mathrm{J}$ A. Corticosteroid treatment in rheumatoid arthritis. $\mathrm{Br} \mathcal{F}$ Rheumatol 1985; 24: 379-81.

3 Gray R G, Gottlieb N L. Intra-articular corticosteroids. Clin Orthop 1983; 177: 235-63.

4 Weiss S, Kisch E S, Fischel B. Systemic effects of intraarticular administration of triamcinolone hexacetonide. Isr $\mathcal{F}$ Med Sci 1983; 19: 83-4.

5 Bertouch J V, Meffin P J, Sallustio B C, Brooks P M. A comparison of plasma methylprednisolone concentrations following intra-articular injection in patients with rheumatoid arthritis and osteoarthritis. Aust NZ 7 Med 1983; 13: 583-6.

6 Liebling M R, Leib E, McLaughlin K, et al. Pulse methylprednisolone in rheumatoid arthritis. A double-blind methylprednisolone in rheumatoid arthritis. A doub
cross-over trial. Ann Intern Med 1981; 94: 21-6.

7 Forster P J G, Grindulis K A, Neumann V, Hubball S, McConkey B. High-dose intravenous methylprednisolone in rheumatoid arthritis. Ann Rheum Dis 1982; 41: 444-6.

8 Williams J A, Baylis E M, Shipley M E. A double blind placebo controlled trial of methylprednisolone pulse therapy in active rheumatoid disease. Lancet 1982; ii: $237-40$.

9 Neumann V, Hopkins R, Dixon J, Watkins A, Bird H, Wright V. Combination therapy with pulsed methyl44: 747-51.

10 Bertouch J V , Roberts-Thomson P J, Smith M D, Woodruff T G, Brooks P M, Bradley J. Methylprednisolone infusion therapy in rheumatoid arthritis patients. The effect on synovial fluid lymphocyte subsets and inflammatory indices. synovial fluid lymphocyte subsets
Arthritis Rheum 1986; 29: 32-7.

11 Hansen T M, Dickmeiss E, Jans H, Hansen T I, IngemannNielsen M, Lorenzen I B. Combination of methylprednisolone pulse therapy and remission inducing drugs in rheumatoid arthritis. Ann Rheum Dis 1987; 46: 290-5.

12 Smith M D, Bertouch J V, Smith A M, et al. The clinical and immunological effects of pulse methylprednisolone therapy in rheumatoid arthrits. I. Clinical effects. $\mathcal{F}$ Rheumatol 1988; 15: $229-32$.

13 Shipley M E, Bacon P A, Berry H, et al. Pulsed methylprednisolone in active early rheumatoid disease: A doseprednisolone in active early rheumatoid disease:
ranging study. $B r \mathcal{F}$ R heumatol 1988; 27: $211-4$.

14 The Cooperating Clinics Committee of the American Rheumatism Association. A controlled trial of gold salt therapy in rheumatoid arthritis. Arthritis Rheum 1973; 16: 353-8.

15 Isang I K, Patterson C A, Steib H J B, Robinson H S, Ford D K. D-penicillamine in the treatment of rheumatoid arthritis. Arthritis Rheum 1977; 20: 666-70.

16 Lockie L M, Smith D M. Forty-seven years experience with gold therapy in 1,019 rheumatoid arthritis patients. Semin Arthritis Rheum 1985; 14: 238-46.

17 Smith M D, Ahern M J, Roberts-Thomson P J. Pulse steroid therapy in rheumatoid arthritis: Can equivalent doses of oral prednisolone give similar clinical results to intravenous methylprednisolone? Ann Rheum Dis 1988; 47: 28-33.

18 Needs C J, Smith M, Boutagy J, et al. Comparison of methylprednisolone (l g IV) with prednisolone (1 g orally) methylprednisolone ( 1 g IV) with prednisolone (1 g orally) in rheumatoid arthritis: a pharmacoki
study. $\mathcal{F}$ R heumatol 1988; $15: 224-8$.

19 Walters M T, Cawley M I D. Combined suppressive drug treatment in severe refractory rheumatoid disease: an analysis of the relative effects of parenteral methylprednisolone, cyclophosphamide, and sodium aurothiomalate. Ann Rheum Dis 1988; 47: 924-9.

20 Williams I A, Mitchell A D, Rothman W, Tallett P, Williams $K$, Pitt $P$. Survey of the long term incidence of osteonecrosis of the hip and adverse medical events in rheumatoid arthritis after high dose intravenous methylprednisolone. Ann Rheum Dis 1988; 47: 930-3.

21 Radia M, Furst D E. Comparison of three pulse methylprednisolone regimens in the treatment of rheumatoid prednisolone regimens in the treatment
arthritis. F R heumatol 1988; 15: 242-6.

22 Garrett R, Paulus H. Complications of intravenous methylprednisolone pulse therapy in rheumatoid arthritis. Arthritis Rheum 1980; 23: 677.

23 Jones J G. Avascular necrosis and pulsed methylprednisolone in RA. Br f Rheumatol 1988; 27: 497-8.

24 Bijlsma J W J, Duursma S A, Huber-Bruning O. Bone metabolism during methylprednisolone pulse therapy in
rheumatoid arthritis. Ann Rheum Dis 1986; 45: 757-60.

25 Bijlsma J W J, Duursma S A, Bosch R, Raymakers J A, Huber-Bruning $O$. Acute changes in calcium and bone metabolism during methylprednisolone pulse therapy in rheumatoid arthritis. Br F Rheumatol 1988; 27: 215-9.

26 Smith M D, Ahern M J, Brooks P M, Roberts-Thomson P J. The clinical and immunological effects of pulse methylprednisolone therapy in rheumatoid arthritis. II. Effects on immune and inflammatory indices in peripheral blood. f Rheumatol 1988; 15: 233-7.

27 Smith M D, Ahern M J, Brooks P M, Roberts-Thomson $P$ J. The clinical and immunological effects of pulse methylprednisolone therapy in rheumatoid arthritis. III. Effects on immune and inflammatory indices in synovial fluid. I Rheumatol 1988; 15: 238-41.

28 Baylis E M, Williams I A, English J. High dose intravenous methylprednisolone "pulse" therapy in patients with rheu-
matoid disease. Eur F Clin Pharmacol 1982; 21: 385-8.

29 Barry $M$. The use of high-dose pulse methylprednisolone in rheumatoid arthritis. Unproved therapy. Arch Intern Med 1985; 145: 1483-4.

30 Kraus A. Pulse steroid therapy, rheumatoid arthritis and the Journal of Rheumatology. F Rheumatol 1988; 15: 1872.

31 Sebaldt $R$ J. Pulse steroid therapy and the search for improved drug therapy of rheumatoid arthritis. $f$ Rheumatol 1988; 15: 200-1.

32 Fan P T, Yu D T Y, Clements P J, Fowlston S, Eisman J, Bluestone $R$. Effect of corticosteroids on the human immune response: comparison of one and three daily $1 \mathrm{gm}$ intravenous pulses of methylprednisolone. $\mathcal{F}$ Lab Clin Med 1978; 91: 625-34.

33 Smith M D. Disease-modifying antirheumatic drugs: gold, penicillamine, antimalarials and sulfasalazine. Current Opinions in Rheumatology 1989; 1: 74-9. 